\title{
Pengembangan Media Interaktif Gerakan Yoga Berbasis Mobile Android Menggunakan Metode User Centered Design
}

\author{
${ }^{1}$ Melinne Maldini Rosady, ${ }^{2}$ Banu Santoso* \\ ${ }^{1}$ Sistem Informasi, Fakultas Ilmu Komputer, Universitas Amikom Yogyakarta, Indonesia \\ ${ }^{2}$ Teknik Komputer, Fakultas Ilmu Komputer, Universitas Amikom Yogyakarta, Indonesia \\ *e-mail: banu@amikom.ac.id
}

(received: 18 Maret 2021, revised: 25 Juni 2021, accepted: 23 Juli 2021)

\begin{abstract}
Abstrak
Perubahan gaya hidup masyarakat Indonesia sebagian sudah mengarah ke pola kehidupan modern. Peningkatan ilmu dan teknologi yang sangat berkembang pada masa kini secara tidak langsung cenderung membuat tubuh jadi kurang bergerak (low body movement). Pada zaman milenial ini olahraga sangatlah diperlukan, selain untuk menjaga agar tubuh tetap sehat, olahraga juga dapat membuat badan menjadi lebih ideal. Kini kian banyak orang yang memperlakukan yoga sebagai kebutuhan utama, bukan semata gaya hidup. Yoga ini diyakini banyak orang bermanfaat bagi kesehatan fisik dan psikis. Yoga merupakan seni olah tubuh, pernafasan, dan pikiran dalam bentuk gerakan-gerakan yang bersifat flowing, continue dinamis, ataupun gerakan yang ditahan dalam beberapa kali hitungan dan dibantu dengan olah pernafasan dan meditasi ringan. Oleh karena itu dalam penelitian ini diajukan suatu aplikasi membuat Media Interaktif berbasis mobile android gerakan yoga sebagai media pembelajaran tentang Gerakan yoga yang memiliki kemampuan dalam membantu user dan sesuai dengan kebutuhan user. Pada penelitian ini pengalaman pengguna aplikasi gerakan yoga di evaluasi dengan 2 metode yaitu User-Centered Design (UCD) dan System Usability Scale (SUS). Pada pengujian UCD dilakukan saat mulainya perancangan sebuah aplikasi, sedangkan selanjutnya aplikasi di uji kelayakan dengan menggunakan metode SUS. Hasil penelitian pembuatan Media Interaktif Gerakan Yoga berbasis mobile android memperoleh skor kelayakan sebesar 75,3\% atau masuk dalam kategori B (Baik).
\end{abstract}

Kata Kunci: media interaktif, yoga, aplikasi android, user centered design, system usability scale

\begin{abstract}
Part of the change in the lifestyle of the Indonesian people has led to modern life patterns. Increasing science and technology, which is significantly developed today, indirectly tends to make the body less mobile (low body movement). In this millennial era, exercise is essential. Apart from keeping the body healthy, exercise can also make the body more ideal. Now more and more people treat yoga as a primary need, not just a lifestyle. Many people believe yoga to be beneficial for physical and psychological health. Yoga is the art of exercising the body, breathing, mind in flowing, continuous dynamic movements, or movements held for several counts and assisted by breathing exercises and light meditation. Therefore, in this study, an application is proposed to create interactive media based on mobile android yoga movements as a learning medium about yoga movements that can help users according to user needs. In this study, the user experience of the yoga movement application was evaluated by two methods, namely the User-Centered Design (UCD) and the System Usability Scale (SUS). The UCD test is carried out at the start of designing an application, while then the application is tested for feasibility using the SUS method. The research results on mobile Android-based Yoga Movement Interactive Media obtained a feasibility score of $75.3 \%$ or included in category B (Good).
\end{abstract}

Keywords: interactive media, yoga, android application, user centered design, system usability scale 


\section{Pendahuluan}

Multimedia interaktif [1] merupakan pemanfaatan computer untuk menggabungkan text, grafik, audio, foto bergerak (video serta animasi) dengan link dan tool yang cocok sehingga memungkinkan pembuat dapat melakukan navigasi, berinteraksi, berkreasi, serta komunikasi. Sejalan dengan itu menurut Prastowo [2], "Bahan ajar interaktif adalah kombinasi dari dua atau lebih media (audio, teks, grafik, gambar dan video) yang oleh penggunanya dimanipulasi untuk mengendalikan perintah dan atau perilaku alami dari suatu presentasi". Sekarang ini, sudah mulai banyak orang yang memanfaatkan bahan ajar interaktif, karena di samping menarik, bahan ajar ini juga memudahkan bagi penggunanya dalam mempelajari materi.

Salah satu pengimplementasian media interaktif ini [3] adalah pada pembelajaran gerakan yoga. Yoga merupakan aktivitas olahraga tubuh serta pik iran yang fokus pada kekuatan, kelenturan serta respirasi untuk meningkatkan kekuatan jasmani dan rohani. Dua komponen utama yoga adalah pernapasan dan postur gerakan.

Untuk membuat media interaktif pembelajaran yoga yang memiliki tingkat kegunaan yang baik, maka media interaktif harus disusun dengan pendekatan kepada pengguna. Menurut Hidayah, dkk [4], mengungkapkan bahwa User Centered Design (UCD) ialah model pengembangan yang difokuskan pada peranan user dalam memastikan kebutuhannya.

Melihat hal ini peneliti berinisiatif untuk membuat penelitian dengan judul, Pengembangan Media Interaktif Gerakkan Yoga Berbasis Mobile Android Menggunakan Metode User Centered Design.

\section{Tinjauan Pustaka}

Untuk mempermudah jalannya penelitian ini maka peneliti melakukan peninjauan kepada beberapa penelitian pada bidang yang sama. Hal ini dimaksudkan agar peneliti dapat melakukan perbandingan terhadap penelitian-penelitian yang sudah pernah dilakukan sebelumnya. Berikut ini merupakan beberapa penelitian yang dijadikan referensi oleh peneliti.

Tabel 1. Ikhtisar Penelitian

\begin{tabular}{|c|c|c|c|}
\hline Peneliti/Tahun & Lokasi & Kontribusi Penelitian & Metode \\
\hline $\begin{array}{l}\text { Setyo, } \\
\text { / } 2016[5]\end{array}$ & Dekstop & $\begin{array}{l}\text { Merancang dan membangun aplikasi } \\
\text { latihan fitness untuk pemula }\end{array}$ & $\begin{array}{lr}\text { Diagram } & \text { HIPO } \\
\text { (Hierarchi } & \text { Input } \\
\text { Process Output) } & \end{array}$ \\
\hline $\begin{array}{l}\text { I Gst, dkk/ } \\
2017 \text { [6] }\end{array}$ & Android & 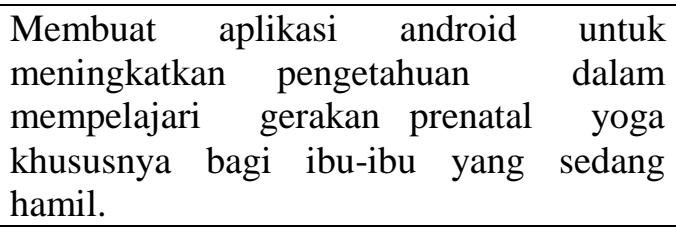 & Metode Model ADDIE \\
\hline $\begin{array}{l}\text { Kadek, } \\
\text { dkk/ } 2019 \text { [7] }\end{array}$ & Android & $\begin{array}{l}\text { Media pembelajaran yang menarik dan } \\
\text { mudah dipelajari sekaligus menjadi acuan } \\
\text { dalam mempelajari gerakan Hatha Yoga } \\
\text { dan Surya Namaskara selain di buku. }\end{array}$ & Extreme Programming \\
\hline $\begin{array}{l}\text { I Putu, } \\
\mathrm{dkk} / 2019[8]\end{array}$ & Desktop & $\begin{array}{l}\text { Menghasilkan aplikasi } \\
\text { interaktif yang dapat } \\
\text { informasi kepada pengguna. }\end{array}$ & Metode Model Delphi \\
\hline $\begin{array}{l}\text { Putra, } \\
\text { dkk/ } 2020 \text { [9] }\end{array}$ & Android & $\begin{array}{l}\text { Meningkatkan minat masyarakat } \\
\text { mengenai gerakan yoga. }\end{array}$ & MDLC \\
\hline Penelitian ini & Android & $\begin{array}{l}\text { Merancang, membangun } \\
\text { mengimplementasikan sebuah } \\
\text { yang dapat memudahkan para } \\
\text { untuk berlatih gerakan yoga } \\
\text { otodidak tanpa instruktur. } \\
\text { otodia }\end{array}$ & $\begin{array}{l}\text { User centered design, } \\
\text { system usability scale, } \\
\text { MDLC }\end{array}$ \\
\hline
\end{tabular}

Berdasarkan Ikhtisar Penelitian Tabel 1 terdapat beberapa perbedaan-perbedaan metode yang diusulkan sebagai kontribusi positif dalam penelitian. Penelitian yang dilakukan oleh Setyo Wibowo pada tahun 2016 [5] yang membahas tentang merancang dan membuat aplikasi latihan fitness untuk 
pemula berbasis multimedia. Metode yang digunakan pada penelitian ini merupakan diagram HIPO. Kelebihan dari penelitian ini merupakan aplikasi ini disajikan dengan gambar dan video animasi sehingga mudah dipahami. Kekurangan pada penelitian ini adalah tidak dapat dijalankan di aplikasi operasi android.

Penelitian yang dilakukan oleh I Gst Putu Bagus Naramas Wahyu Prayoga, I Ketut Resika Arthana, I Gede Mahendra Darmawiguna pada tahun 2017 [6] yang membahas tentang membuat aplikasi android untuk meningkatkan pengetahuan dalam mempelajari gerakan prenatal yoga khususnya bagi ibu-ibu yang sedang hamil. Metode yang digunakan pada penelitian ini merupakan metode model ADDIE. Kelebihan dari penelitian ini merupakan aplikasi yang ditampilkan sudah dalam bentuk 3D animasi. Kekurangan pada penelitian ini adalah ukuran file yang cukup besar.

Penelitian yang dilakukan oleh Kadek Ardiago, Machudor Yusman, Wayan Rumite pada tahun 2019 [7] yang membahas tentang media pembelajaran yang menarik dan mudah untuk dipelajari. Metode yang digunakan pada penelitian ini merupakan extreme programming. Kelebihan dari penelitian ini merupakan tampilan aplikasi telah sinkron dan proporsional dengan semua macam resolusi layar yang telah diuji coba. Kekurangan pada penelitian ini adalah belum tersedianya alarm pengingat waktu.

Penelitian yang dilakukan oleh I Putu Caesar Andika Putra, Muhammad Rusli, I Ketut Putu Suniantara pada tahun 2019 [8] yang membahas tentang menghasilkan aplikasi multimedia interaktif yang dapat memberikan informasi kepada pengguna. Metode yang digunakan pada penelitian ini merupakan metode model delphi. Kelebihan dari penelitian ini merupakan antar-muka aplikasi sudah user friendly. Kekurangan pada penelitian ini adalah aplikasi ini perlu pengembangan dalam Bahasa inggris.

Penelitian yang dilakukan oleh Putra Arya Nanda pada tahun 2020 [9] yang membahas tentang meningkatkan minat masyarakat mengenai gerakan yoga. Metode yang digunakan pada penelitian ini merupakan MDLC. Kelebihan dari penelitian ini adalah aplikasi bisa langsung di instalasi di smartphone mobile seperti android tanpa harus membuka dengan aplikasi eclipse lagi. Kekurangan pada penelitian ini adalah belum tersedianya fitur seperti zoom-in untuk memperbesar video gerakan yoga agar tampak lebih jelas.

Sedangkan penelitian ini membahas tentang merancang, membangun dan mengimplementasikan sebuah aplikasi yang dapat memudahkan para pemula untuk berlatih gerakan yoga secara otodidak tanpa instruktur. Metode yang digunakan adalah user centered design, MDLC, system usability scale. Kelebihan dari penelitian ini adalah aplikasi berbasis offline sehingga tidak memerlukan internet untuk mengaksesnya. Kekurangan dari penelitian ini adalah ukuran aplikasi terlalu besar.

\section{A. Multimedia}

Multimedia secara etimologis bermula dari kata multi dan media [10]. Multi memiliki makna banyak dan media memiliki makna sarana untuk memberikan paparan atau penjelasan seperti gambar, teks, video, suara. Jadi secara bahasa multimedia merupakan gabungan beberapa sarana media seperti gambar, teks, video, suara, yang dipakai untuk memberikan pesan atau penjelasan. Pengertian ini masih sangat umum, belum secara spesifik menunjukkan bagaimana bentuk dan proses pembuatannya.

\section{B. Interaksi Manusia dan Komputer}

Interaksi komputer manusia [11] adalah memenuhi kebutuhan pengguna sehingga desain produk interaktif dapat mendukung kebutuhan tersebut. Produk-produk interaktif akan gagal menarik minat pengguna jika pengguna merasa kesulitan untuk berinteraksi dengan produk-produk tersebut. Sedangkan Supriyanta [12] menjelaskan bahwa interaksi manusia dan komputer adalah sebuah hubungan antara manusia dan komputer yang mempunyai karakteristik tertentu untuk mencapai suatu tujuan tertentu dengan menjalankan sebuah sistem yang menggunakan antarmuka. 


\section{User Centered Design}

UCD (User Centered) [13] memiliki arti paradigma baru dalam pengembangan sistem berbasis web. Perancangan berbasis pengguna (User Centered Design) merupakan istilah untuk menggambarkan filosofi perancangan. pengguna sebagai pusat dari proses pengembangan sistem, tujuan/sifat-sifat, konteks dan semua lingkungan sistem didasarkan dari pengalaman pengguna yang merupakan konsep dari UCD. Pada Gambar 1 menunjukkan metode User Centered Design.

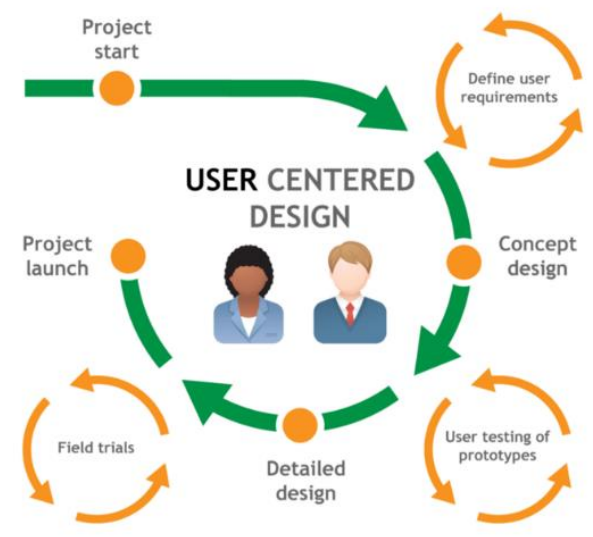

\section{Gambar 1. Metode User Centered Design [13]}

\section{Multimedia Development Life Cycle}

Multimedia Development Life Cycle [14] merupakan metode pengembangan program multimedia yang dilakukan dalam 6 tahap, yaitu concept (pengonsepan), design (perancangan), material collecting (pengumpulan bahan), assembly (pembuatan), testing (pengujian), dan distribution (pendistribusian). Ke-enam tahap tidak perlu dilakukan secara berurutan, walaupun tahap concept harus dilakukan pertama.

\section{E. System Usability Scale (SUS)}

System Usability Scale (SUS) [15] adalah metode evaluasi yang menghasilkan sesuatu yang memadai berdasarkan pertimbangan jumlah sampel yang sedikit, waktu, dan biaya. Hasil dari perhitungan metode SUS dikonversi ke dalam sebuah nilai, yang dapat dijadikan pertimbangan untuk menentukan apakah sebuah aplikasi tersebut sudah layak atau tidak layak untuk diterapkan.

\section{F. Android}

Android [16] merupakan salah satu sistem operasi perangkat mobile berbasis Linux yang mencakup sistem operasi, middleware dan aplikasi. Android memberikan platform terbuka bagi para pengembang untuk menciptakan aplikasi. Pada mulanya, Google Inc membeli Android Inc yang merupakan pendatang baru yang membuat perangkat lunak untuk smartphone. Kemudian untuk mengembangkan Android, dibangun Open Handset Alliance, konsorsium dari 34 perusahaan perangkat keras, perangkat lunak dan telekomunikasi, termasuk Google, HTC, Intel, Motorola, Qualcomm, T-Mobile, dan Nvidia.

Pada saat pengumuman pertama Android, 5 November 2007, Android bersama Open Handset Alliance menyatakan mensupport pengembangan open source pada perangkat mobile. Di lain pihak, Google merilis kode-kode Android di bawah lisensi Apache, sebuah lisensi perangkat lunak dan open platform perangkat seluler.

\section{Metode Penelitian}

Pada penelitian ini menggunakan alat penelitian berupa perangkat keras dan perangkat lunak sebagai tools untuk merancang Aplikasi Gerakan Yoga adalah laptop Lenovo 80LD AMD A6-7310 APU with AMD Radeon R4 Graphic (4CPUs), 2.0GHz, memori RAM 8 GB, HDD 500 GB, Grafis AMD Radeon R4 Graphic, Kamera Sony A6000, Sistem operasi Windows 10 64bit, program aplikasi Adobe Animate CC 2018, CorelDRAW X8, Adobe Premiere CC 2015, script Actionscript 3.0. 
Pada penelitian ini akan menerapkan media interaktif aplikasi gerakan yoga dengan metode User Centered Design (UCD), Multimedia Development Life Cycle (MDLC), serta metode evaluasi yaitu System Usability Scale (SUS).

Selanjutnya jalan penelitian ini dimulai dari survei pendahuluan dengan melakukan pendefinisian masalah yang akan diangkat kedalam penelitian, tahap selanjutnya pengumpulan data pendukung penelitian yang menghasilkan informasi seperti persona pengguna dan lain sebagainya, kemudian dilakukan perancangan dan implementasi UCD untuk membuat sejumlah persiapan yang dibutuhkan dalam melakukan survei. Persiapan yang dilakukan seperti penyusunan pertanyaan dan atau pernyataan yang akan digunakan pada kuesioner, lalu Data hasil UCD akan dianalisis pada tahap ini. Data dari pengujian UCD akan menghasilkan User Requirements yaitu kebutuhan dari pengguna yang disesuaikan dengan tujuan pembuatan media interaktif. Selanjutnya UCD akan diimplementasikan kedalam media interaktif menggunakan Adobe Animate, lalu dilakukan Evaluasi Media Interaktif Menggunakan SUS, lalu hasil tersebut dianalisis untuk menghasilkan kesimpulan yang menjadi jawaban atas tujuan penelitian.

\section{Hasil Dan Pembahasan}

\section{A. Perancangan Sistem}

Struktur Navigasi Menu dapat dilihat pada Gambar 2. Aplikasi gerakan yoga berisi tentang informasi yoga berbasis mobile android dengan metode User centered Design.

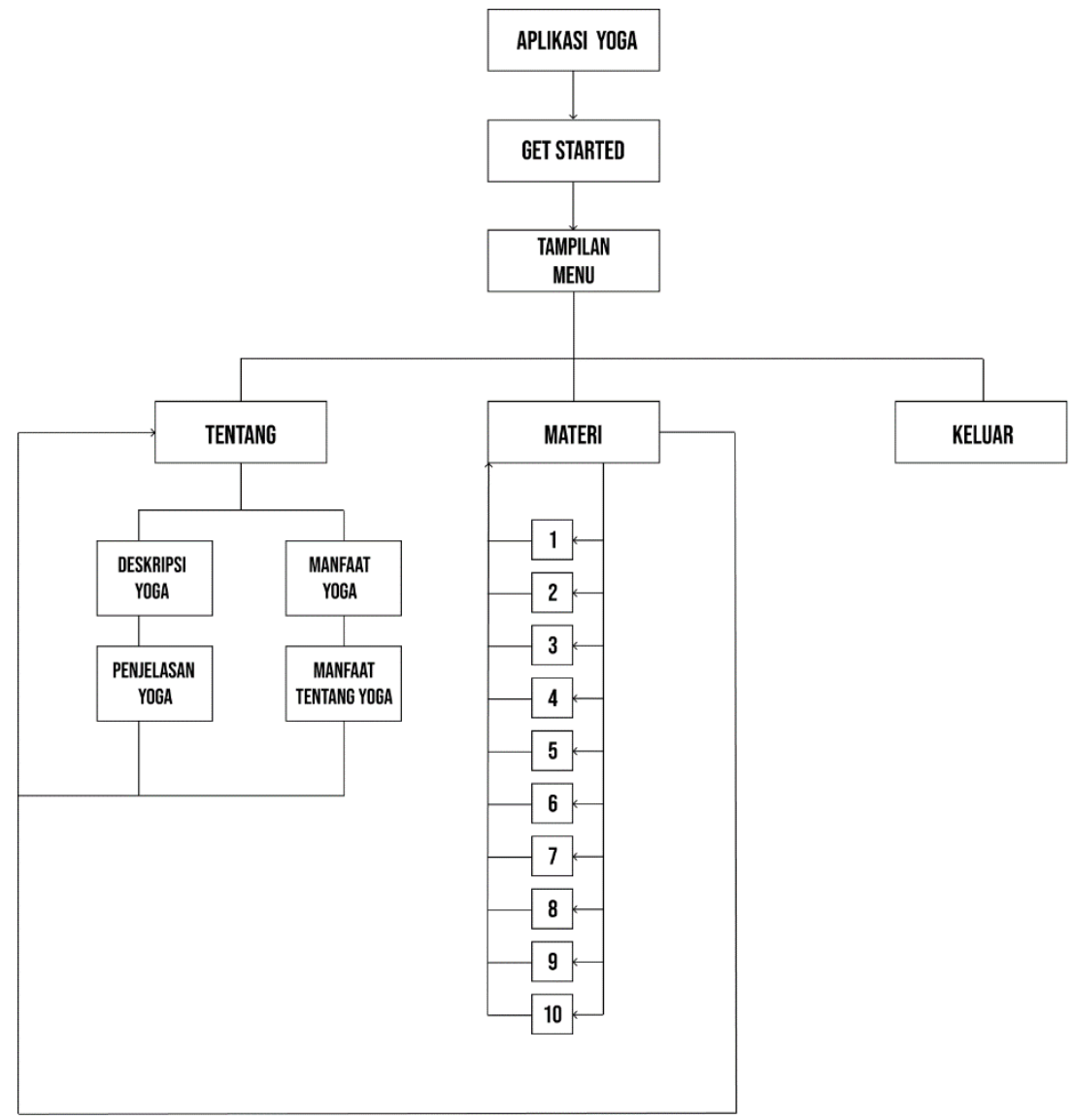

Gambar 2. Struktur Navigasi Menu

Pada Gambar 3 menggambarkan alur aplikasi halaman utama. Flowchart menjelaskan tahapan dari berjalannya sistem secara runtut mulai dari halaman get started, menu utama dan menu materi dan tentang. 


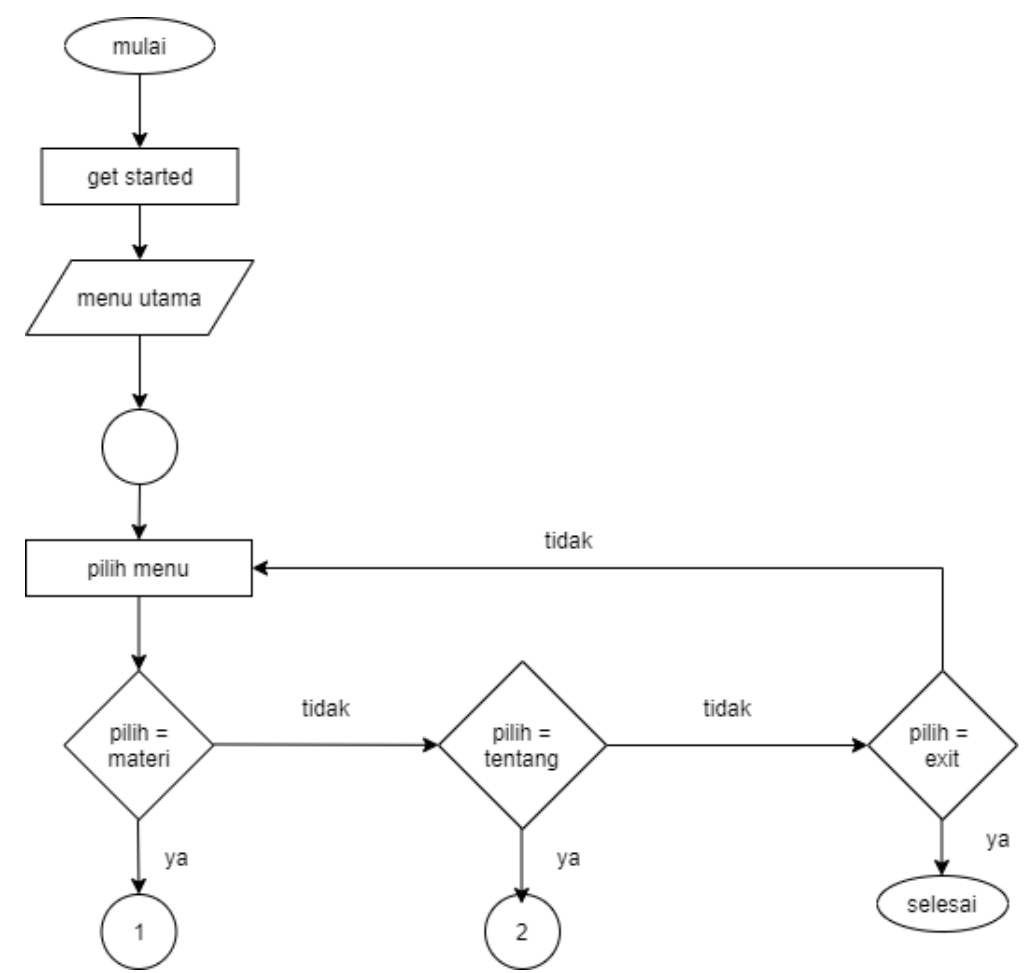

Gambar 3. Flowchart

Saat Aplikasi dijalankan terdapat button get started, setelah menekan button get started, lalu akan muncul pilihan materi dan tentang, jika mengakses "Materi" akan masuk ke halaman gerakan yoga dan jika mengakses 'Tentang" akan masuk ke halaman deskripsi dan manfaat tentang yoga.

\section{B. Implementasi Sistem}

Antarmuka awal adalah tampilan awal setelah aplikasi Android Gerakan Yoga dijalankan. Pada menu awal terdapat tombol Get Started untuk melanjutkan ke halaman selanjutnya. Pada Gambar 4 menunjukkan antarmuka awal.

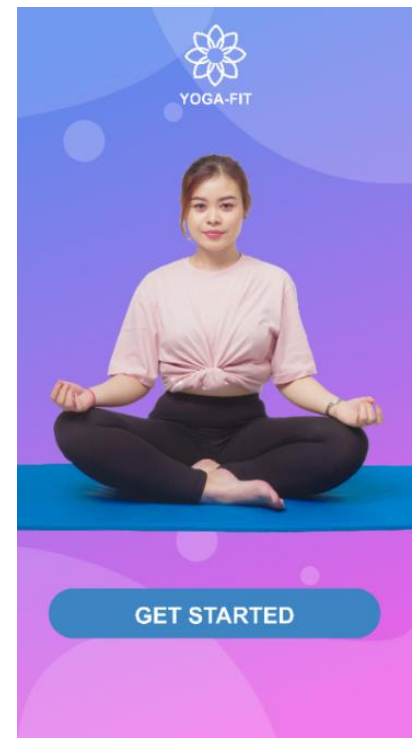

\section{Gambar 4. Antarmuka Awal}

Antarmuka menu utama merupakan tampilan utama aplikasi Android Gerakan Yoga. Pada menu utama terdapat tiga tombol menu yang dapat dipilih oleh pengguna aplikasi. Ketiga tombol menu yang dimaksud adalah: tombol materi, tombol tentang dan tombol exit. Tombol materi untuk menampilkan halaman materi gerakan yoga, tombol tentang untuk menampilkan halaman keterangan 
tentang yoga, tombol exit untuk keluar dari aplikasi. Pada Gambar 5 menunjukkan antarmuka menu utama.

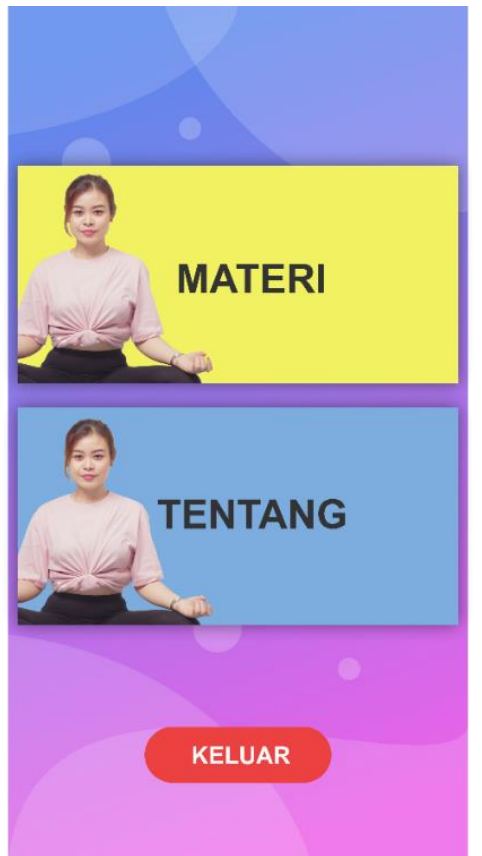

\section{Gambar 5. Antarmuka Menu Utama}

Antarmuka menu utama merupakan tampilan utama aplikasi Android Gerakan Yoga dan terdapat tombol materi Ketika di pilih maka akan menampilkan pilihan materi gerakan yoga 1 sampai dengan 10. Pada Gambar 6 menunjukkan antarmuka menu materi.

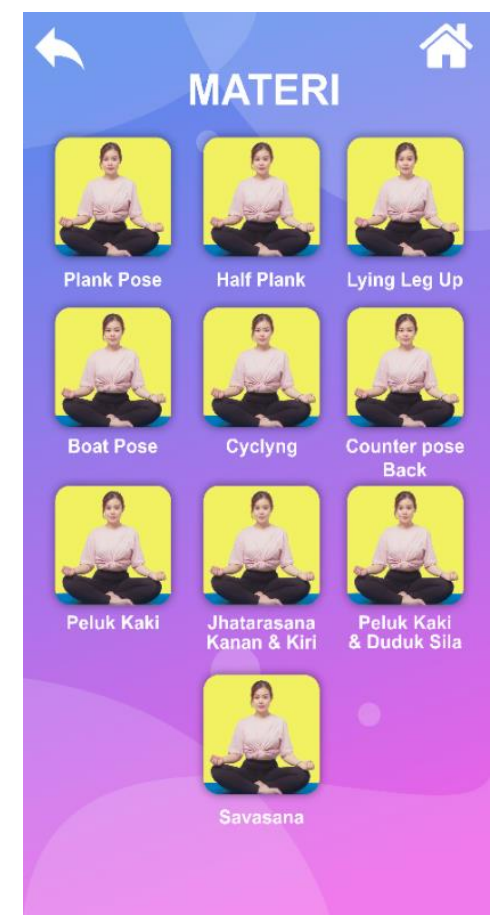

\section{Gambar 6. Antarmuka Materi}

Antarmuka menu gerakan yoga akan muncul, jika tombol pilihan gerakan pada menu materi di pilih. Sehingga, akan menampilkan video gerakan yoga dan keterangan gerakan tersebut. Pilihlah tombol gerakan secara urut mulai dari 1 sampai dengan 10. Pada Gambar 7 menunjukkan antarmuka halaman gerakan yoga. 

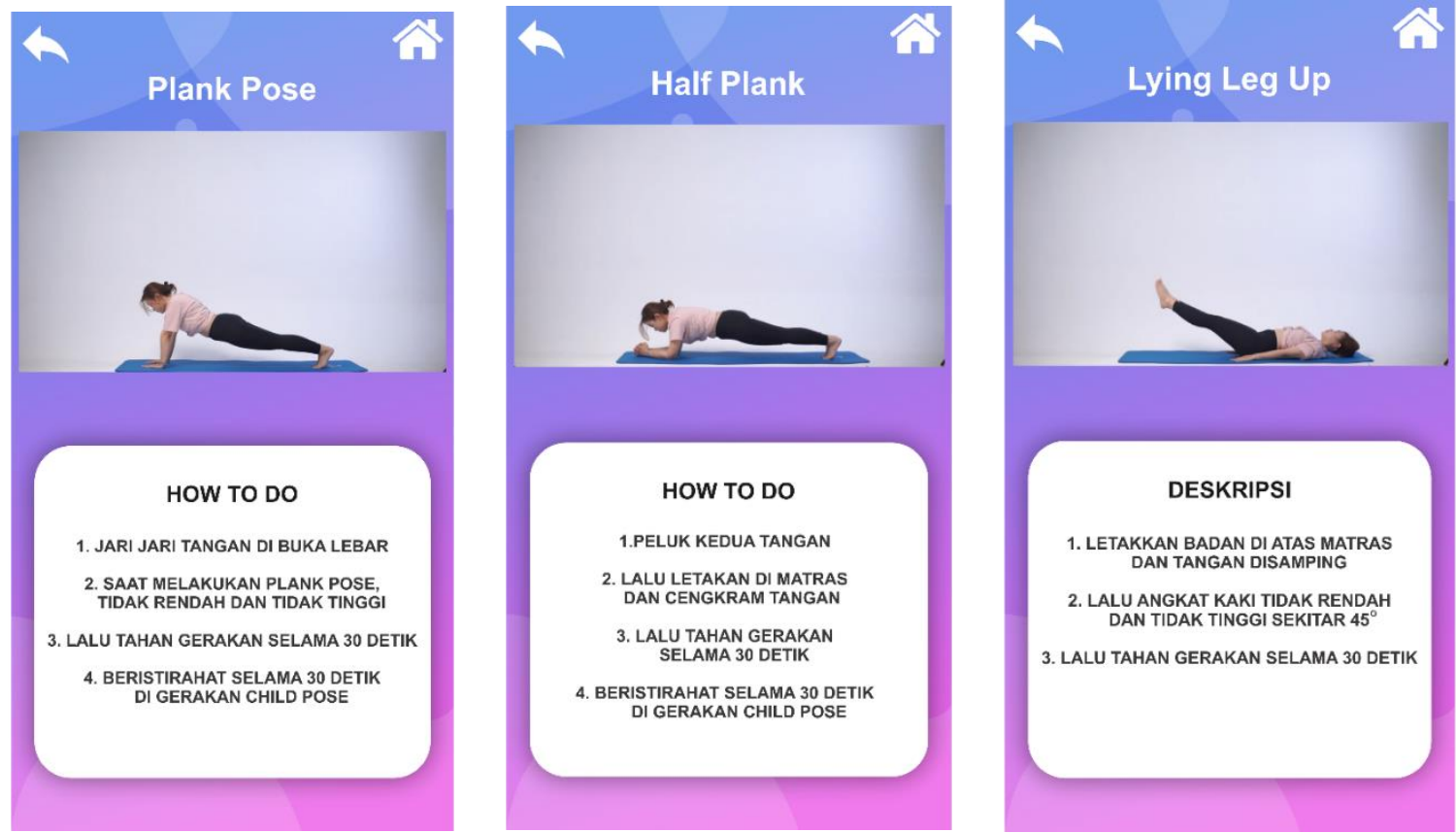

Gambar 7. Antarmuka Halaman Gerakan Yoga

Antarmuka menu tantang akan muncul, jika tombol menu tentang pada menu utama di pilih. Sehingga akan menampilkan halaman menu tentang yang berisi tentang deskripsi dan manfaat yoga, yang ditunjukkan pada Gambar 8.

\section{Pengujian Sistem}

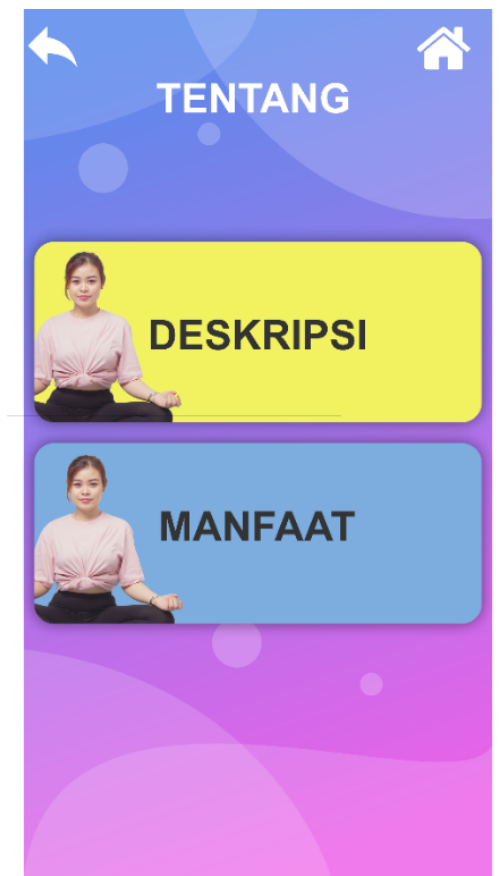

\section{Gambar 8 Antarmuka Menu Tentang}

\section{Pengujian Blackbox Testing}

Pengujian pada tahap ini menggunakan metode Blackbox Testing. Metode blackbox merupakan pengujian program berdasarkan fungsi dari program dengan tujuan untuk menemukan kesalahan fungsi pada program. Pengujian blackbox berfokus pada persyaratan fungsional perangkat lunak dan berdasarkan pada storyboard, naskah dan struktur navigasi yang telah dibuat. Pada blackbox testing ini peneliti melakukan testing pada setiap scene/halaman untuk melihat animasi dan fungsi button yang ada pada setiap scene/halaman. Hasil pengujian dapat dilihat pada Tabel 2. 
Tabel 2. Hasil Uji Fungsionalitas

\begin{tabular}{|c|c|c|c|c|}
\hline No. & $\begin{array}{c}\text { Fungsi } \\
\text { Skenario Uji }\end{array}$ & $\begin{array}{c}\text { Hasil yang } \\
\text { Diharapkan }\end{array}$ & Hasil & Kesimpulan \\
\hline 1. & $\begin{array}{l}\text { Halaman } \\
\text { SplashScreen }\end{array}$ & $\begin{array}{l}\text { Menampilkan animasi logo sebagai } \\
\text { pembuka Media Interaktif }\end{array}$ & Sukses & Valid \\
\hline 2. & $\begin{array}{l}\text { Tombol Menu } \\
\text { Awal }\end{array}$ & $\begin{array}{l}\text { Menampilkan halaman awal saat } \\
\text { aplikasi telah dibuka dengan satu } \\
\text { tombol yaitu get started }\end{array}$ & Sukses & Valid \\
\hline 3. & $\begin{array}{l}\text { Tombol } \\
\text { Halaman Menu } \\
\text { Utama }\end{array}$ & $\begin{array}{l}\text { Menampilkan beberapa tombol yaitu } \\
\text { materi, tentang, dan Exit }\end{array}$ & Sukses & Valid \\
\hline 4. & $\begin{array}{l}\text { Tombol Menu } \\
\text { Materi }\end{array}$ & $\begin{array}{l}\text { Menampilkan tombol gerakan-gerakan } \\
\text { yoga, plank pose, half plank, lying leg } \\
\text { up dll }\end{array}$ & Sukses & Valid \\
\hline 5. & $\begin{array}{l}\text { Tombol } \\
\text { gerakan-gerakan } \\
\text { yoga }\end{array}$ & $\begin{array}{l}\text { Menampilkan video praktik secara } \\
\text { Live gerakan yoga, menampilkan } \\
\text { langkah-langkah melakukan Gerakan } \\
\text { yoga }\end{array}$ & Sukses & Valid \\
\hline 6. & $\begin{array}{ll}\text { Tombol } & \text { Menu } \\
\text { Tentang } & \\
\end{array}$ & $\begin{array}{l}\text { Menampilkan dua pilihan, deskripsi } \\
\text { atau manfaat yoga }\end{array}$ & Sukses & Valid \\
\hline 7. & $\begin{array}{l}\text { Tombol Menu } \\
\text { Deskripsi }\end{array}$ & $\begin{array}{l}\text { Menampilkan informasi terkait dengan } \\
\text { Deskripsi Yoga }\end{array}$ & Sukses & Valid \\
\hline 8. & $\begin{array}{l}\text { Tombol Menu } \\
\text { Manfaat }\end{array}$ & $\begin{array}{l}\text { Menampilkan informasi terkait dengan } \\
\text { Manfaat Yoga }\end{array}$ & Sukses & Valid \\
\hline 9. & Tombol Keluar & Keluar dari aplikasi & Sukses & Valid \\
\hline
\end{tabular}

Berdasarkan pengujian alpha menggunakan metode blackbox testing yang telah dilakukan, diperoleh hasil bahwa aplikasi media interaktif gerakan yoga yang dibuat telah memenuhi persyaratan fungsional. Dimana aplikasi yang dibuat sudah dapat menghasilkan keluaran yang diharapkan berdasarkan pada storyboard, naskah dan struktur navigasi.

\section{Pengujian Pengguna Tahap Satu}

Merujuk pada data pada Tabel 3, dapat disimpulkan bahwa hasil pengujian tiap user dengan 12 pertanyaan menghasilkan respon yang bermacam-macam. Maka perlu adanya sebuah ringkasan terhadap respon user. Berikut ini adalah ringkasan respon yang diberikan oleh user.

\section{Tabel 3. Hasil Kuesioner UCD}

\begin{tabular}{|c|c|c|}
\hline No. & Aspek Yang Dinilai & \begin{tabular}{|l} 
Kesimpulan Jawaban \\
\end{tabular} \\
\hline 1. & $\begin{array}{l}\text { Silahkan pilih satu dari beberapa } \\
\text { warna berikut: } \\
\text { - Merah } \\
\text { - Biru } \\
\text { - Hijau }\end{array}$ & $\begin{array}{l}\text { Pada pertanyaan pertama mayoritas responden memilih } \\
\text { jawaban warna biru. }\end{array}$ \\
\hline 2. & $\begin{array}{l}\text { Kenapa anda memilih warna } \\
\text { tersebut? }\end{array}$ & $\begin{array}{l}\text { Dapat di simpulkan jawaban dari responden memilih } \\
\text { warna biru karena warna biru memiliki kenyamanan saat } \\
\text { di lihat dan warna tersebut juga warna favorit semua } \\
\text { orang. }\end{array}$ \\
\hline 3. & $\begin{array}{l}\text { Bagaimana pendapat anda tentang } \\
\text { yoga? }\end{array}$ & $\begin{array}{l}\text { Dapat di simpulkan jawaban dari responden tentang yoga } \\
\text { yaitu yoga adalah olahraga yang menyenangkan } \\
\text { dilakukan dan dapat dilakukan dimana saja. }\end{array}$ \\
\hline 4. & $\begin{array}{l}\text { Apakah anda sudah pernah } \\
\text { melakukan yoga? }\end{array}$ & $\begin{array}{l}\text { Dapat disimpulkan bahwa dari beberapa user masih ada } \\
\text { yang baru memulai yoga, dan mayoritas sudah pernah }\end{array}$ \\
\hline
\end{tabular}




\begin{tabular}{|c|c|c|}
\hline No. & Aspek Yang Dinilai & $\begin{array}{r}\text { Kesimpulan Jawaban } \\
\end{array}$ \\
\hline & & melakukan yoga. \\
\hline & $\begin{array}{l}\text { Apa yang anda rasakan setalah } \\
\text { melakukan yoga? }\end{array}$ & $\begin{array}{l}\text { Dari beberapa user yang sudah pernah melakukan yoga } \\
\text { bahwa setelah melakukan yoga badan dan pikiran terasa } \\
\text { lebih segar, dan badan terasa lebih sehat dari } \\
\text { sebelumnya. }\end{array}$ \\
\hline & $\begin{array}{l}\text { Apa pendapat Anda tentang } \\
\text { aplikasi tutorial gerakan yoga? }\end{array}$ & $\begin{array}{l}\text { Bagi mereka yang baru memulai atau sudah pernah } \\
\text { melakukan yoga, tutorial gerakan yoga sangat membantu } \\
\text { dan mudah digunakan. }\end{array}$ \\
\hline & $\begin{array}{l}\text { Jika dibuat sebuah aplikasi yoga, } \\
\text { fitur apa yang anda ingin masukkan } \\
\text { kedalamnya? }\end{array}$ & $\begin{array}{l}\text { Kebanyakan dari user membutuhkan fitur seperti tutorial } \\
\text { gerakan yoga beserta tata cara melakukan yoga tersebut, } \\
\text { deskripsi, dan manfaat yoga. }\end{array}$ \\
\hline & $\begin{array}{l}\text { Mengapa anda ingin memasukkan } \\
\text { fitur tersebut? }\end{array}$ & $\begin{array}{l}\text { Dapat disimpulkan dari responden fitur tersebut } \\
\text { dibutuhkan bagi para pemula yoga untuk lebih mengenal } \\
\text { yoga. }\end{array}$ \\
\hline & $\begin{array}{l}\text { Apakah anda pernah melakukan } \\
\text { latihan yoga secara online? }\end{array}$ & Mayoritas user sudah pernah latihan secara online. \\
\hline & $\begin{array}{l}\text { Bagaimana pengalaman anda } \\
\text { setelah melakukan yoga online? }\end{array}$ & $\begin{array}{l}\text { Setelah melakukan yoga online mayoritas user sangat } \\
\text { terbantu untuk melakukan yoga kapan dan dimana saja. }\end{array}$ \\
\hline & $\begin{array}{l}\text { Jika anda mengikuti kelas yoga } \\
\text { online, bahasa pengantar apa yang } \\
\text { ingin anda gunakan? Kenapa anda } \\
\text { ingin menggunakan bahasa } \\
\text { pengantar tersebut? }\end{array}$ & $\begin{array}{l}\text { Dapat disimpulkan mayoritas user memilih kata } \\
\text { pengantar Bahasa Indonesia dan ada beberapa yang } \\
\text { memilih Bahasa inggris. Jadi aplikasi gerakan yoga } \\
\text { menggunakan dua bahasa yaitu Bahasa Indonesia dan } \\
\text { Bahasa inggris. }\end{array}$ \\
\hline & $\begin{array}{l}\text { Jika anda mengikuti kelas yoga } \\
\text { online, anda lebih suka melihat } \\
\text { gerakan yoga dengan video atau } \\
\text { gambar? Kenapa anda lebih } \\
\text { menyukai hal tersebut? }\end{array}$ & $\begin{array}{l}\text { Dapat disimpulkan jawaban dari user memilih gerakan } \\
\text { yoga dengan video karena lebih mudah untuk di } \\
\text { praktekan dan mudah di ingat. }\end{array}$ \\
\hline
\end{tabular}

Menurut uji User Centered Design, mayoritas user memberikan jawaban yang beragam. Dihimpun dari feedback yang di berikan user, aplikasi gerakan yoga membutuhkan beberapa fitur seperti tutorial gerakan yoga dengan video selain mudah untuk dipraktekkan, tutorial dengan video mudah diingat. Selain itu user merasa perlu adanya penambahan informasi seperti deskripsi tentang yoga sehingga user dapat mengenal yoga lebih dalam.

\section{Pengujian Pengguna Tahap Dua}

System Usability Scale (SUS) berisi 10 pernyataan, dimana sampel diberikan skala 1 sampai 5 untuk menjawab berdasarkan tingkat kesetujuan dengan setiap pernyataan terhadap produk atau fitur yang kita uji. Selanjutnya peneliti menyusun Google Form sebagai media pengisian kuesioner. Hasil dari pengisian kuesioner ini berupa karakteristik sampel dan tanggapan responden terhadap penyataan yang diajukan. Total responden yang didapat pada pengujian SUS ini adalah 35 orang. Pada Tabel 4 menunjukkan tabel pengujian System Usability Scale.

Merujuk pada hasil data yang diolah pada tabel 4, aplikasi Media Interaktif Gerakan Yoga memiliki nilai rata-rata sebesar 75.3. Sehingga aplikasi Media Interaktif Gerakan Yoga memiliki nilai skala penilaian B (baik) dalam pengujian usability dengan metode System Usability Scale (SUS). Maka dengan score 75.3 aplikasi memiliki score yang layak untuk direkomendasikan. 
Tabel 4. Pengujian System Usability Scale

\begin{tabular}{|c|c|c|c|c|c|c|c|}
\hline \multirow[b]{2}{*}{ No. } & \multirow[b]{2}{*}{ Responden } & \multicolumn{5}{|c|}{ Frekuensi Jawaban } & \multirow[b]{2}{*}{ Jumlah } \\
\hline & & 5 & 4 & 3 & 2 & 1 & \\
\hline 1 & $\begin{array}{l}\text { Saya pikir saya akan sering } \\
\text { menggunakan aplikasi Gerakan } \\
\text { Yoga }\end{array}$ & 12 & 38 & 12 & 0 & 0 & 62 \\
\hline 2 & $\begin{array}{l}\text { Saya merasa aplikasi Gerakan Yoga } \\
\text { terlalu rumit padahal dapat dibuat } \\
\text { lebih sederhana. }\end{array}$ & 0 & 0 & 12 & 96 & 35 & 143 \\
\hline 3 & $\begin{array}{l}\text { Saya rasa aplikasi Gerakan Yoga } \\
\text { ini mudah untuk digunakan. }\end{array}$ & 11 & 48 & 0 & 0 & 0 & 59 \\
\hline 4 & $\begin{array}{l}\text { Saya pikir saya membutuhkan } \\
\text { bantuan dari orang teknis untuk } \\
\text { dapat menggunakan aplikasi } \\
\text { Gerakan Yoga ini. }\end{array}$ & 0 & 4 & 15 & 88 & 30 & 137 \\
\hline 5 & $\begin{array}{l}\text { Saya menemukan bahwa terdapat } \\
\text { berbagai macam fungsi yang } \\
\text { terintegrasi dengan baik dalam } \\
\text { aplikasi Gerakan Yoga. }\end{array}$ & 3 & 36 & 36 & 4 & 5 & 84 \\
\hline 6 & $\begin{array}{l}\text { Saya rasa banyak hal yang tidak } \\
\text { konsisten terdapat pada aplikasi } \\
\text { Gerakan Yoga. }\end{array}$ & 0 & 8 & 39 & 56 & 20 & 123 \\
\hline 7 & $\begin{array}{l}\text { Saya rasa mayoritas pengguna akan } \\
\text { dapat mempelajari aplikasi Gerakan } \\
\text { Yoga dengan cepat. }\end{array}$ & 18 & 34 & 0 & 0 & 0 & 52 \\
\hline 8 & $\begin{array}{l}\text { Saya menemukan bahwa aplikasi } \\
\text { Gerakan Yoga sangat tidak praktis } \\
\text { ketika digunakan. }\end{array}$ & 0 & 10 & 36 & 60 & 15 & 121 \\
\hline 9 & 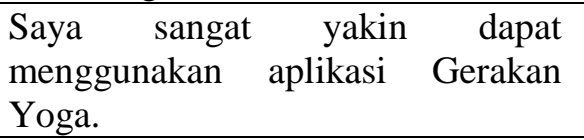 & 14 & 38 & 3 & 4 & 0 & 59 \\
\hline 10 & $\begin{array}{l}\text { Saya harus belajar banyak hal } \\
\text { terlebih dahulu sebelum saya dapat } \\
\text { menggunakan aplikasi Gerakan } \\
\text { Yoga. }\end{array}$ & 0 & 0 & 18 & 68 & 60 & 146 \\
\hline & Skor Penyataan Ge & & & & & & 495 \\
\hline & Skor Penyataan Ga & & & & & & 559 \\
\hline & Total Skor & & & & & & 1054 \\
\hline & Total Skor * 2.5 & & & & & & 2635 \\
\hline & Jumlah Respond & & & & & & 35 \\
\hline & Rata-rata Nilai & & & & & & 75.3 \\
\hline & Skala Penilaian & & & & & & $\mathrm{B}$ \\
\hline & Keterangan & & & & & & Baik \\
\hline
\end{tabular}

\section{Kesimpulan}

Berdasarkan hasil penelitian dan pembahasan dalam Pengembangan Media Interaktif Gerakan Yoga Berbasis Mobile Android Menggunakan Metode User Centered Design, dapat disimpulkan bahwa penelitian ini menghasilkan aplikasi media interaktif gerakan yoga berbasis mobile android yang dapat membantu pengguna dalam berlatih gerakan yoga. Berdasarkan pengujian yang telah dilakukan, aplikasi ini dapat berjalan baik sesuai fungsionalitas dan berdasarkan pengujian kebergunaan diperoleh rata-rata yaitu 75.3 yang berarti masuk dalam nilai skala penilaian B (Baik). 
Media interaktif gerakan yoga ini mampu menambah fungsi smartphone sebagai alat pembelajaran. Karena dapat dimanfaatkan untuk proses latihan gerakan yoga.

\section{Referensi}

[1] M. Jalaludin, "Perkembangan Teknologi Multimedia," www.medium.com, 2019. https://medium.com/multimedia-tech/perkembangan-teknologi-multimedia-496fdd7db3b0.

[2] A. Prastowo, Panduan Kreatif Membuat Bahan Ajar Inovatif. Yogyakarta: DIVA press, 2015.

[3] A. B. I. Noya, "Yoga untuk Pemula," www.alodokter.com, 2017. https://www.alodokter.com/tidak-perlu-bertubuh-lentur-untuk-ikut-yoga.

[4] N. Hidayah, M. Zain, A. Jaafar, F. Hanis, and A. Razak, "a User-Centered Design: Methodological Tools To Design and Develop Computer Games for Motor-Impaired Users," 5th Int. Conf. Comput. Informatics ICOCI 2015, no. 130, pp. 223-228, 2015, [Online]. Available: http://www.uum.edu.my.

[5] S. Wibowo, "Perancangan Aplikasi Latihan Fitness Untuk Pemula Berbasis Multimedia," Tek. Inform. Univ. PGRI Yogyakrta, August, 2016.

[6] I. G. M. D. I Gst Putu Bagus Naramas Wahyu Prayoga, I Ketut Resika Arthana, "Pengembangan Aplikasi Augmented Reality Markerless Pengenalan Dan Teknik Dasar Prenatal Yoga," Kumpul. Artik. Mhs. Pendidik. Tek. Inform., vol. 6, no. 3, p. 247, 2017, doi: 10.23887/karmapati.v6i3.12058.

[7] K. Ardiago, M. Yusman, and W. Rumite, “C 2019 Ilmu Komputer Unila Publishing Network all right reserve Jurnal Komputasi Aplikasi Pembelajaran Yoga Hindu Berbasis Android Pendahuluan (C) 2019 Ilmu Komputer Unila Publishing Network all right reserve Jurnal Komputasi Metodologi Penelitian,” vol. 7, no. 1, pp. 62-69, 2019.

[8] A. P. I Putu Caesar, M. Rusli, and I. K. P. Suniantara, "Aplikasi Multimedia Interaktif Pengenalan Olahraga Aeromodelling,” Sensitif, pp. 957-963, 2019.

[9] P. A. Nanda, "Simulasi Visualisasi Teknik Gerakan Yoga Dengan Metode Pengembangan Multimedia Luther-Sutopo Berbasis Mobile," vol. 7, no. 2, pp. 207-213, 2020, doi: 10.30865/jurikom.v7i2.1944.

[10] H. Surjono, Multimedia Pembelajaran Interaktif: Konsep dan Pengembangan, no. April. 2017.

[11] S. N. A. S. Juhriyansyah Dalle, Ariffin Abdul Mutalib, Nassiriah Shaari, Pengantar Interaksi Manusia dan Komputer. PT RajaGrafindo Persada, Depok, 2019.

[12] Supriyanta, Interaksi Manusia dan Komputer. Yogyakarta:Deepublish, 2015.

[13] V. R. Mendapara, Y. R. Ghodasara, G. S. Poriya, and K. C. Kamani, "User-Centered Design ( UCD ) Approach for Designing of Platform Independent Applications in Smartphone," Int. J. Adv. Res. Comput. Commun. Eng., vol. 4, no. 12, pp. 268-272, 2015, doi: 10.17148/IJARCCE.2015.41262.

[14] H. Sugiarto, "Penerapan Multimedia Development Life Cycle Pada Aplikasi Pengenalan Abjad Dan Angka," IJCIT (Indonesian J. Comput. Inf. Technol., vol. Vol.3 No.1, no. 1, pp. 26-31, 2018.

[15] B. Pudjoatmodjo and R. Wijaya, "Tes Kegunaan (Usability Testing) Pada Aplikasi Kepegawaian Dengan Menggunakan System Usability Scale," Semin. Nas. Teknol. Inf. dan Multimed. 2016, pp. 37-42, 2016.

[16] "The Google Geocoding API," Google Developer. https://developers.google.com/maps/docume ntation/geocoding/. 